\title{
IMPACTO DA DESIDRATAÇÃO POR MICRO-ONDAS NOS COMPOSTOS BIOATIVOS DA SPIRULINA PLATENSIS
}

\author{
A. O. SANTOS ${ }^{1}$, T. C. $\operatorname{SILVA}^{1}$, N. C. $\operatorname{SILVA}^{1}$, C. R. DUARTE ${ }^{1}$ e M. A. S. BARROZO ${ }^{1}$ \\ ${ }^{1}$ Universidade Federal de Uberlândia, Faculdade de Engenharia Química \\ E-mail para contato: andy.oliveiras@ hotmail.com
}

\begin{abstract}
RESUMO - Spirulina platensis, também conhecida como alga verde-azulada, é um microrganismo fotossintetizante e uma fonte de nutrientes essenciais. Entretanto, devido ao seu elevado conteúdo de água, essa microalga sofre um rápido processo de degradação quando armazenada em condições in natura. Logo, torna-se necessário adotar métodos de secagem para um melhor aproveitamento deste material, sendo que o uso de micro-ondas tem se destacado devido a sua rapidez e eficiência energética. $O$ presente trabalho avaliou os efeitos da desidratação por micro-ondas na microalga Spirulina platensis e seus impactos nos compostos bioativos (fenólicos, flavonoides, ácido cítrico e ficocianina). Verificou-se que, apesar da desidratação ter ocasionado degradação dos compostos em relação ao material in natura, foi possível encontrar condições ótimas de operação para um possível aproveitamento da Spirulina.
\end{abstract}

\section{INTRODUÇÃO}

As microalgas são microrganismos fotossintetizantes de estrutura celular simples que se encontram distribuídos tanto em água doce quanto em águas salgadas. Encontram-se categorizados em diversas classes, distinguindo-se principalmente pela sua pigmentação, ciclo de vida e estrutura celular básica. Dentre as microalgas de maior destaque, encontra-se a Spirulina, cujo principal pigmento é a ficocianina e que possui propriedades antioxidantes, anti-inflamatória e hepatoprotetora. A Spirulina é também uma fonte segura e natural de nutrientes essenciais, tais como: pró-vitaminas, minerais e ácidos graxos poli-insaturados e possui uma parede celular constituída de peptidoglicanos, o que faz de suas células digeríveis (Miranda et al., 1998; Tomaselli, 1997).

Em decorrência do seu alto valor nutricional, há um crescente interesse em estudos em biotecnologia alimentar utilizando a Spirulina. Contudo essa microalga possui uma quantidade significativa de água, podendo sofrer um processo de degradação quando úmida, fazendo com que a desidratação seja uma alternativa para obtenção da biomassa a fim de aumentar sua vida útil (Oliveira et al., 2010). Dentre os métodos de desidratação, destacamse o uso de micro-ondas. Essa radiação eletromagnética tem a habilidade de penetrar os materiais e aquecê-los volumetricamente, ou seja, em toda a sua extensão e de dentro da fora (Datta \& Anantheswaran, 2001). Apesar de ser um método recente, tem mostrado oferecer vantagens similares aos métodos convencionais, com alguns benefícios como: tempos de processamento reduzidos e economia de energia (Venkatesh \& Raghavan, 2004). 
Deste modo, o presente trabalho tem como objetivo investigar o efeito de diferentes potências de micro-ondas na desidratação da Spirulina platensis, avaliando o seu impacto em termos de compostos bioativos, verificando a viabilidade para um possível aproveitamento da biomassa dessa microalga.

\section{MATERIAIS E MÉTODOS}

\subsection{Resíduo utilizado}

A microalga Spirulina platensis utilizada neste trabalho foi fornecida pela empresa Brasil Vital, localizada em Anápolis - GO. As amostras foram separadas, empacotadas em pacotes plásticos transparentes, envolvidas em papel alumínio e congeladas em freezer até o momento dos experimentos.

\subsection{Aparato experimental}

A desidratação da microalga Spirulina platensis foi realizada em um micro-ondas doméstico de potência nominal de $800 \mathrm{~W}$. Para que fosse possível acompanhar a remoção de umidade sem necessidade de parar ou abrir o equipamento, foi acoplada uma balança à parte superior do mesmo (Figura 1a). Os experimentos foram realizados nas potências de 280, 480, 600 e $800 \mathrm{~W}$ sendo o material desidratado até uma faixa de umidade inferior a $8 \%$, onde foi observado, em todas as condições, baixos valores de atividade de água (Celestino, 2010).

Figura 1 - Sistema de Micro-ondas utilizado (a) e amostra de Spirulina (b)
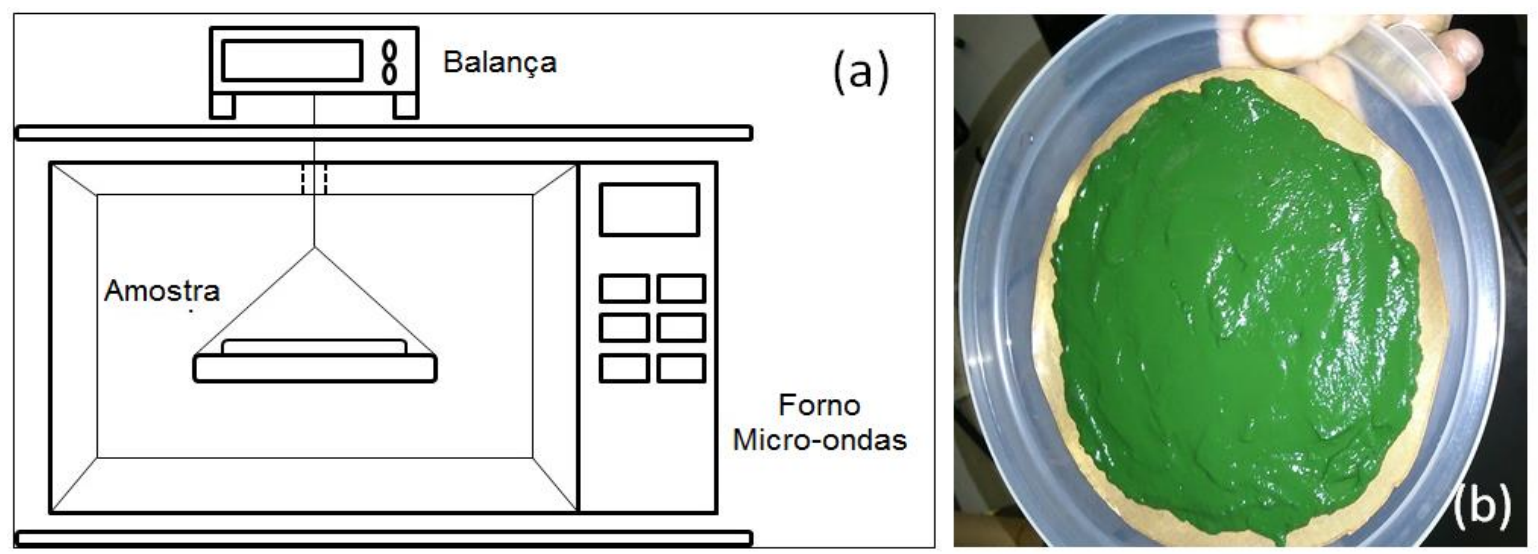

\subsection{Análises realizadas}

$\mathrm{O}$ teor de umidade foi determinado através método da estufa a $105 \pm 3^{\circ} \mathrm{C}$ por 24 horas (AOAC, 1995) enquanto que as medições de atividade de água (Aw) foram efetuadas no equipamento Lab-Swift AW (Novasina).

Quanto aos teores de compostos bioativos, o Teor de Fenólicos Totais (TPC) foi determinado pelo método de Folin Ciocalteau (Singleton \& Rossi, 1965), utilizando ácido gálico como padrão e leitura em espectrofotômetro a $622 \mathrm{~nm}$. Os resultados foram expressos em mg ácido gálico/100 g de amostra seca. Já o Teor de Flavonoides Totais (TFC) foi 
determinado utilizando o método colorimétrico descrito por Zhishen et al. (1999), utilizando rutina como padrão e leitura em espectrofotômetro a $450 \mathrm{~nm}$. Os resultados foram expressos em $\mathrm{mg}$ rutina/100 $\mathrm{g}$ de amostra seca. A Acidez (ATT) foi determinada através de titulação das amostras com $\mathrm{NaOH}$ padronizado até a viragem (AOAC, 1995). Os resultados foram expressos em mg de ácido cítrico / $100 \mathrm{~g}$ de amostra em base seca. E por último, o Teor de Ficocianina (TF) foi realizado pelo método descrito por Costa et al. (2015), através da leitura das amostras em espectrofotômetro nas absorbâncias de 620 e $652 \mathrm{~nm}$. Os resultados foram expressos em $\mathrm{g}$ ficocianina/100 $\mathrm{g}$ em base seca.

\section{RESULTADOS E DISCUSSÕES}

\subsection{Spirulina in natura}

Os teores dos compostos bioativos obtidos na Spirulina platensis in natura, isto é, antes da desidratação, estão expressos na Tabela 1. Constatou-se um alto teor de umidade, justificando a necessidade da secagem. Observou-se também a presença de compostos bioativos importantes, com destaque para a ficocianina, comprovando o potencial nutritivo da microalga. Tais resultados serão utilizados como base de comparação para o material após a desidratação.

Tabela 1 - Teores dos compostos bioativos da Spirulina in natura.

\begin{tabular}{|c|c|}
\hline Análises & Resultados \\
\hline Fenólicos (mg / 100 g base seca) & $252,40 \pm 13,97$ \\
\hline Flavonoides (mg / 100 g base seca) & $4,83 \pm 0,25$ \\
\hline Acidez (mg / 100 g base seca) & $2173,68 \pm 179,32$ \\
\hline Ficocianina (g/ 100 g base seca) & $8,75 \pm 0,51$ \\
\hline Umidade $(\%)$ & $82,40 \pm 0,92$ \\
\hline
\end{tabular}

\subsection{Umidade final e atividade de água (Aw)}

A atividade de água é um dos fatores mais importantes durante o processo de desidratação, pois quantifica a água disponível para a proliferação de microrganismos e as reações de degradação que podem prejudicar os alimentos durante seu armazenamento. Estudos têm mostrado que a faixa ideal para que não ocorra o crescimento de microrganismos nem essas reações indesejadas é entre 0,3 - 0,5 (Celestino, 2010), faixa essa observada ao término de todos os experimentos realizados, conforme pode ser observado na Tabela 2.

Observou-se também que a potência impactou diretamente a remoção de umidade da microalga. Verificou-se que quanto maior a potência, menor a umidade de água, a atividade 
de água e o tempo de desidratação. Entretanto ainda é preciso avaliar os impactos dessas potências nos teores de compostos bioativos.

Tabela 2 - Umidade e atividade de água da Spirulina após as secagens.

\begin{tabular}{|c|c|c|c|}
\hline POTÊNCIA & $\begin{array}{c}\text { Umidade Final } \\
(\%)\end{array}$ & $\begin{array}{c}\text { Atividade de Água } \\
(\text { Aw })\end{array}$ & $\begin{array}{c}\text { Tempo de } \\
\text { Desidratação (seg) }\end{array}$ \\
\hline $280 \mathrm{~W}$ & $6,62 \pm 0,26$ & 0,426 & 1980 \\
\hline $480 \mathrm{~W}$ & $4,46 \pm 0,19$ & 0,347 & 1080 \\
\hline $600 \mathrm{~W}$ & $4,10 \pm 0,08$ & 0,337 & 720 \\
\hline $800 \mathrm{~W}$ & $4,48 \pm 0,23$ & 0,342 & 660 \\
\hline
\end{tabular}

\subsection{Compostos bioativos}

Os resultados obtidos para os compostos bioativos analisados neste trabalho estão expostos na Figura 2.

Figura 2 - Teores de compostos bioativos após a desidratação

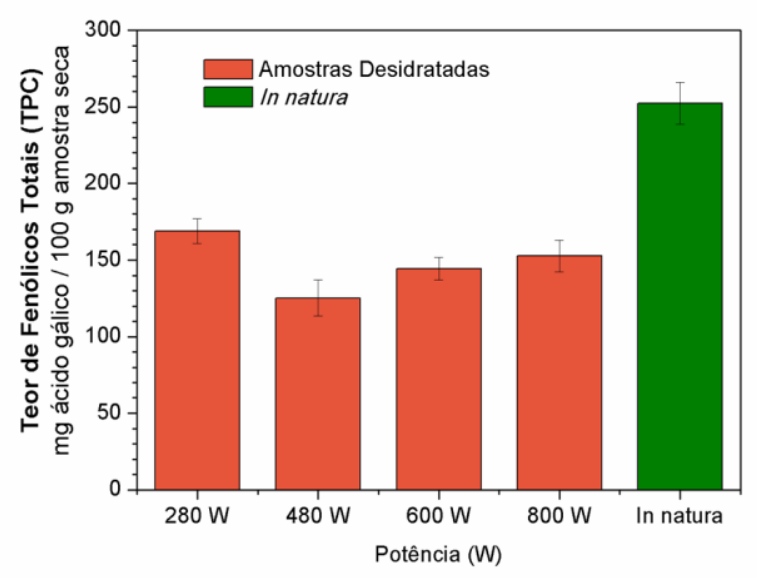

(a)

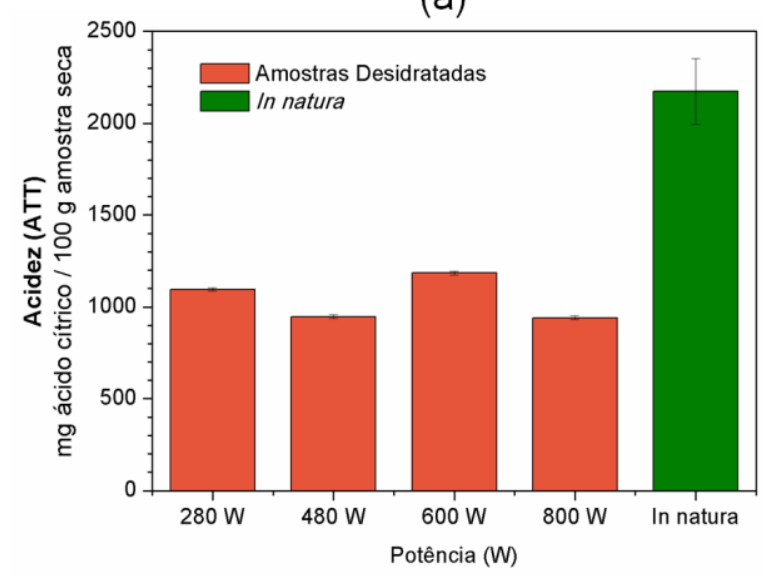

(c)

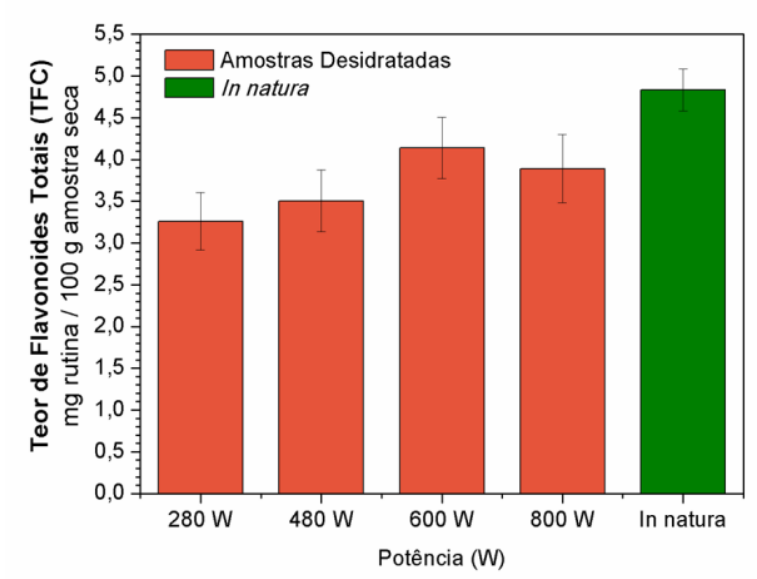

(b)

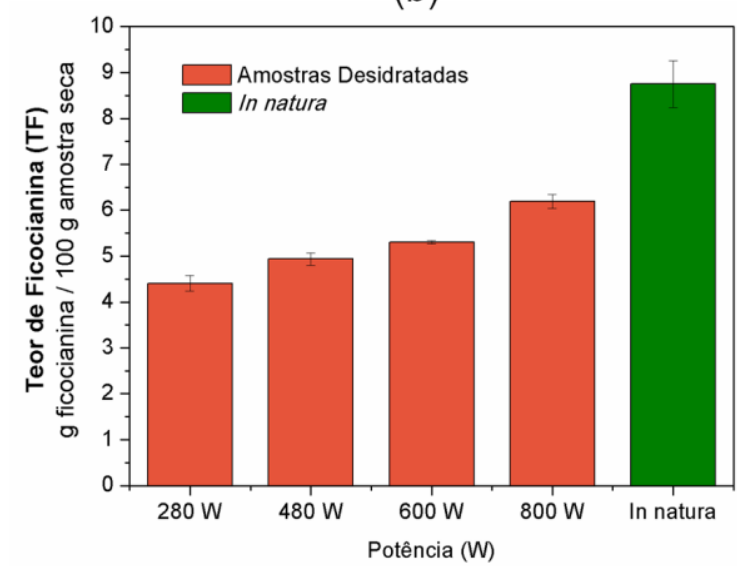

(d) 
Os resultados obtidos para o Teor de Fenólicos Totais (TPC) estão expressos na Figura 2(a). Observou-se que após a desidratação por micro-ondas, a Spirulina apresentou teores inferiores ao do material in natura, indicando que houve um processo de degradação. Apesar da redução do tempo de desidratação observado nas potências mais altas, as mesmas produziram um impacto negativo no TPC. Assim, a potência ideal para esse composto foi de $280 \mathrm{~W}$. Tal comportamento também foi observado por Nakagawa et al. (2016), que verificou que procedimentos que exponham as amostras a temperaturas mais altas causam maior degradação dos compostos presentes na Spirulina.

O Teor de Flavonoides Totais (TFC) obtido nos experimentos está expresso na Figura 2(b). Após a desidratação também foi observado níveis inferiores desse composto em relação ao material in natura, indicando degradação. Entretanto, diferente do observado para os fenólicos, o aumento de potência foi benéfico ao composto, atingindo valores máximos na potência de $600 \mathrm{~W}$. Logo, além da redução do tempo de secagem nas potências mais altas, houve também uma liberação do composto na matriz interna do material durante a remoção de umidade, como relatado por Chism e Haard (1996).

Quanto a Acidez (ATT) (Figura 2(c)), Podsedek (2007) já havia relatado a sensibilidade do ácido cítrico quando exposto a procedimentos de altas temperaturas. Os resultados confirmaram tal comportamento, onde observou-se a degradação do composto, e não houve potência ideal, já que a variação dos valores de acidez foi muito pequena em relação às potências analisadas.

Os resultados obtidos para o Teor de Ficocianina (TF) são apresentados na Figura 2(d). Nakagawa (2016) já havia relatado a termossensiblidade da ficocianina, o que foi observado durante os experimentos, já que os valores de TF obtidos foram inferiores ao da biomassa in natura. Entretanto, analisando-se o efeito da potência, verificou-se que o aumento dessa variável foi benéfico ao composto, atingindo o resultado máximo na potência de $800 \mathrm{~W}$.

\section{CONCLUSÃO}

Assim, pode-se concluir que o processo de desidratação da microalga Spirulina platensis por micro-ondas mostrou-se uma alternativa eficiente para um possível aproveitamento da biomassa desse microrganismo. Apesar da degradação dos compostos bioativos quando comparados ao material in natura, é possível encontrar condições ótimas para futuras aplicações do produto. A potência ideal para o teor de fenólicos totais foi de 280 W, já para o teor de flavonoides foi de $600 \mathrm{~W}$, enquanto que a potência ideal para ficocianina foi de $800 \mathrm{~W}$. Quando a acidez é analisada, observou-se que não houve uma potência ideal, indicando que o ácido cítrico degrada-se até estabilizar e permanecer em um nível constante.

\section{REFERÊNCIAS}

AOAC, Association of Official Analytical Chemists. Official Methods of Analysis, Gaithersburg, MD., 1995.

CELESTINO, S.M.C. Princípios de secagem de alimentos. Planaltina, DF: Embrapa Cerrados, 51p.,2010. 
CHISM, G. W.; HAARD, N. F. Characteristics of edible plant tissues. Em: Food Chem., Fennema, O.R.; Editora Nekker, New York, 3ªEd.; 943-1011. 1996.

COSTA, B. R.; RODRIGUES, M. C.; ROCHA, S. F., POHNDORF, R. S.; LARROSA, A. P.; PINTO, L. A. Optimization of Spirulina sp. Drying in Heat Pump: Effects on the Physicochemical Properties and Color Parameters. J. Food Process. Pres., v. 40(5), p. 934-942, 2015.

DATTA, A.K.; ANANTHESWARAN, R.C. Handbook of Microwave Technology for Food Applications; Marcel Dekker: New York, 2001.

MIRANDA, M.S.; CINTRA, R. G.; BARROS, S.B.M.; MANCINI-FILHO, J. Antioxidant ativity of the microalga Spirulina máxima. Braz. J. Med. Biol. Res., v. 31, p. 10751079, 1998.

NAKAGAWA, K.; RICHAROEN, W.; SRI-UAM, P.; PAVASANT, P.; ADACHIL, S. Antioxidant properties of convective-air-dried Spirulina maxima: Evaluation of phycocyanin retention by a simple mathematical model of air-drying. Food Bioprod. Process., v. 100, p. 292-302, 2016.

OLIVEIRA, E. G.; DUARTE, J.H.; MORAES, K.; CREXI, V.T.; PINTO, L.A.A Optimisation of Spirulina platensis convective drying: evaluation of phycocyanin loss and lipid oxidation. Int. J. Food Sci. Tech., v. 45(8), p. 1572-1578, 2010.

PODSEDEK, A. Natural antioxidants and antioxidant capacity of brassica vegetables: A review, LWT-J. Food Compos. Analysis, v. 40, p. 1-11, 2007.

SINGLETON, V. L.; ROSSI, J. A. Colorimetry of total phenolics with phosphomolibidic acid reagents, Am. J. Enol. Vitic. v. 16, p. 144-158, 1965.

TOMASELLI, L. Morphology, ultrastructure and taxonomy of Arthrospira (Spirulina) maxima and Arthrospira (Spirulina) platensis. In: VONSHAK, A. (Ed.). Spirulina platensis (Arthrospira): physiology, cell-biology and biotechnology. London: Taylor and Francis. Cap. 1, p. 1-15, 1997.

VENKATESH, M.S.; RAGHAVAN, G.S. V. An overview of microwave processing and dieletric properties of agri-food materials, Biosystems Engineering, 88, 1-18. 2004.

ZHISHEN, J.; MENGCHENG, T.; JIANMING, W. The determination of flavonoid contents I n mulberry and their scavenging effects on superoxide radicals, Food Chem., 64, p. 555 $-559,1999$. 